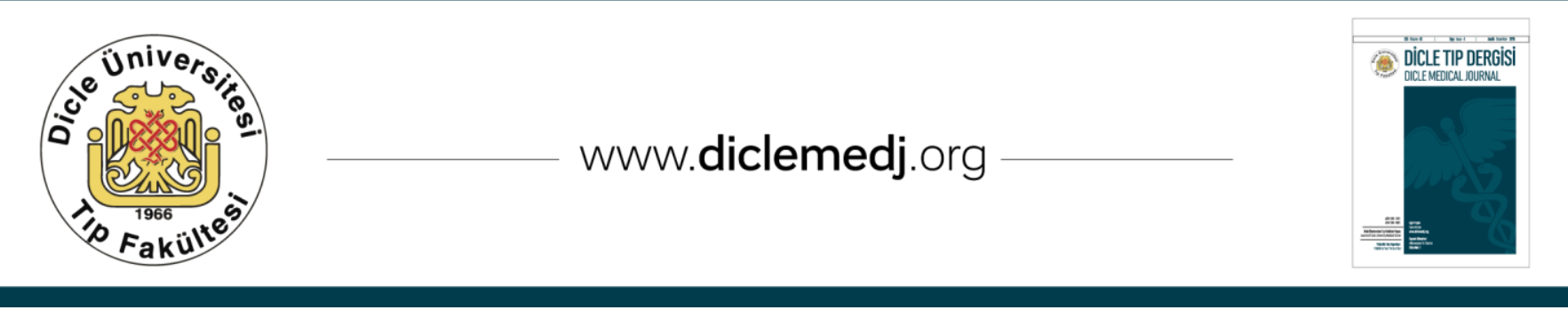

Olgu Sunumu / Case Report

\title{
Bariatrik Cerrahi Sonrası Gelişen ve Guillain Barre Sendromu'nu Taklid Eden Poliradikülonöropati Olgusu
}

\author{
Abdulkadir Tunç¹, Azize Esra Gürsoy², Vildan Güzel ${ }^{3}$ \\ 1 Sakarya Üniversitesi, Sakarya Eğitim ve Araștırma Hastanesi, Nöroloji Kliniği, Sakarya, Türkiye ORCID: 0000-0002-9747-5285 \\ 2 Bezmialem Vakıf Üniversitesi Tıp Fakültesi, Nöroloji Kliniği, İstanbul, Türkiye ORCID: 0000-0002-8103-0927 \\ 3 Bezmialem Vakıf Üniversitesi Tıp Fakültesi, Nöroloji Kliniği, İstanbul, Türkiye ORCID: 0000-0003-4954-6402
}

Geliş: 30.10.2018; Revizyon: 29.01.2019; Kabul Tarihi: 05.02.2019

Öz

Morbid obezite prevalansının artışı ile birlikte bariatrik cerrahi prosedürlerinin sayısı her geçen gün artmakta ve nörolojik komplikasyonlarla daha fazla karşılaşılmaktadır. Bu komplikasyonlar arasında en iyi tanımlanmış olanlar Wernicke ensefalopatisi ve periferik nöropatilerdir. Guillain Barre Sendromu bariatrik cerrahinin çok nadir bir komplikasyonu olarak bildirilmiștir ve bildirilmiş vakalar çoğunlukla aksonal tiptedir. 18 yaşında kadın hasta polikliniğimize kol ve bacaklarda ağrı ve güçsüzlük şikayeti ile başvurdu. Üç ay önce bariatrik cerrahi operasyonu geçirdiği öğrenildi. Alt ekstremitelerde proksimal kas gücü kaybı saptanan hastanın elektrofizyolojik bulguları L3-S1 innerve kaslarda subakut dönem ön kök ön boynuz tutulumu ile uyumlu bulundu. İntravenöz immunglobulin tedavisi sonrası hastada tama yakın düzelme gözlendi. Bariatrik cerrahi sonrası gelişen nörolojik komplikasyonlarda nutrisyonel eksikliklerin yanında enflamatuvar hasarın da göz önünde bulundurulması gerektiği ve bu vakaların kalıcı nörolojik hasarın önlenmesi açısından erken dönemde, multidisipliner bir şekilde takip ve tedavi edilmesi gerektiği görüşündeyiz.

Anahtar kelimeler: Obezite, bariatrik cerrahi, guillain barre sendromu, nöropati

DOI: 10.5798/dicletip.534864

Yazışma Adresi / Correspondence: Abdulkadir Tunç, Sakarya Üniversitesi, Sakarya Eğitim ve Araştırma Hastanesi, Nöroloji Kliniği, Sakarya, Türkiye e-mail: drkadirtunc@hotmail.com 


\title{
A Case of Polyradiculoneuropathy Mimicking Guillain Barre Syndrome after Bariatric Surgery
}

\begin{abstract}
With the rising prevalence of morbid obesity, the numbers of bariatric surgical procedures are also increasing, thus resulting in more neurological complications to be recognized.

Among these complications, the most well-defined are Wernicke's encephalopathy and peripheral neuropathies. Guillain Barre Syndrome (GBS) has been reported as a very rare complication of bariatric surgery and reported cases are mostly axonal types. An 18-year-old female patient applied to our outpatient clinic with complaints of pain and weakness in her arms and legs. She had bariatric surgery 3 months ago. The electrophysiological findings of the patient who had proximal muscle strength loss in the lower extremities were consistent with subacute anterior root anterior horn involvement in the L3-S1 innervated muscles.

After the intravenous immunoglobulin therapy, the patient improved almost completely. We think that in neurological complications after bariatric surgery, nutritional deficiencies should be taken into consideration as well as inflammatory damage and these cases should be followed up and treated in a multidisciplinary manner in order to prevent permanent neurological damage.
\end{abstract}

Keywords: Obesity, bariatric surgery, guillain-barre syndrome, neuropathy.

\section{GİRIŞ}

Bariatrik cerrahi, morbid obezite tedavisinde yaygın kullanımı olan, obezite ile ilişkili erken ölümleri azaltan ve yaşam kalitesini yükselten bir tedavi seçeneğidir ${ }^{1}$. Son yıllarda uygulamaların artması ile bariatrik cerrahi ile ilişkili farklı nörolojik komplikasyonlar da artış göstermiştir. Hastaların yaklaşık \%5'inde gelişebildiği bildirilen bu komplikasyonlar arasında en iyi tanımlanmış olanlar Wernicke ensefalopatisi ve periferik nöropatilerdir ${ }^{2,3}$. Bariatrik cerrahi sonrası gelişen nöropatiler duysal baskın polinöropati, mononöropati ve radikülopleksopatiler olmak üzere 3 farklı paternde tanımlanmıştır ${ }^{4}$. Komplikasyonlar birkaç ay veya yıl içerisinde ortaya çıkabilir. Özellikle polinöropati ve poliradikülonöropati tablolarının, nörolojik komplikasyonların \%51' ini oluşturduğu ve operasyonu takip eden ortalama 3,7 yıl içerisinde ortaya çıktığı bildirilmişsir ${ }^{5}$. B vitamini, folik asit, çinko ve bakır eksiklikleri nörolojik komplikasyonlarla en sık ilişkilendirilen durumlardır ${ }^{4}$. Bunların dışında hızlı kilo verme ve enfeksiyonlara sekonder gelişen immünolojik enflamatuvar mekanizmaların da sorumlu olabileceği bildirilmiștir6 ${ }^{6}$ Periferik sinirleri saran yağ dokusunun sinir kılıfını koruduğu ve bu dokunun kaybı durumunda periferik sinirlerde kompresyona bağlı tuzaklanması sonucu nöropati gelişebileceği de bildirilmiştir ${ }^{7} . \mathrm{Bu}$ çalışmada bariatrik cerrahi sonrası Guillain

Barre sendromu (GBS) benzeri kliniği gelișen ancak elektrofizyoloji ve laboratuvar bulgularının desteklemediği atipik bir poliradikülonöropati olgusu sunulup literatür eşliğinde tartışılması amaçlandı.

\section{OLGU}

18 yaşında sağ elini kullanan kadın hasta polikliniğimize kol ve bacaklarda ağrı ve güçsüzlük şikayeti ile başvurdu. Hikayesinden 3 ay önce bariatrik cerrahi operasyonu geçirdiği öğrenildi. Operasyondan 1 hafta sonra başlayan iştahsızlık, bulantı, kusma atakları ve bacaklarda donukluk hissi şikayetleri ile opere olduğu merkezde yatarak takip edilen hastanın şikayetleri 2. haftada ilerlemiş ve bacaklardan ayaklara doğru uyuşmaları yayılmıștı. Bacaklarda güç kaybı gelişmesi üzerine detaylı tetkikleri yapılan hastanın kranyal ve spinal magnetik rezonans (MR) görüntülemeleri normal izlenmiş, elektrofizyolojik incelemelerinde sural duysal amplitüdlerinin hafif düşük olduğu ve duysal aksonal 
polinöropati ile uyumlu olabileceği belirtilmiști. Bariatrik cerrahi sonrası oluşabilecek vitamin ve mineral eksiklikleri açısından araştırılan hastada sınırda vitamin B12 eksikliği saptanması üzerine siyanokobalamin ve tiamin tedavilerinin verildiği öğrenildi. Özgeçmiş̧inde obezite dışında özellik yoktu (Preop vücut kitle indeksi 35). Sigara, alkol veya madde kullanım öyküsü yoktu. Başvurusunda vitalleri stabil olan hastanın sistemik muayenesi normaldi. Nörolojik muayenesinde hastanın bilinci açık, koopere ve oryante idi. Konuşma akıcı idi, anlaması tamdı. Kranial sinir muayenesi normaldi. Ense sertliği veya meningeal irritasyon bulgusu saptanmadi. Kas gücü muayenesinde, altta bilateral iliopsoas 3/5, quadricepsler $4 / 5$ iken, distal kas güçleri tamdl. Üst esktremitelerde de kas güçleri tam olarak değerlendirildi. Derin tendon refleksleri (biceps, triceps, patella ve aşil) alınamayan hastanın umblikus hizasından aşağı hipoestezisi ve hipoaljezisi mevcuttu. Üriner retansiyon saptanmadi. Altta bilateral pozisyon ve vibrasyon duyusunda azalma kaydedildi. Serebellar sistem muayenesi normaldi.

Taban cildi refleksi bilateral fleksör alındı. Laboratuvar tetkiklerinde ve dış merkezde yapılan görüntülemelerinde özellik saptanmayan hastanin vitamin ve mineral düzeyleri normal sinırlardaydı. Elektrofizyolojik incelemesinde sinir iletim çalışmaları, F yanıtları ve $\mathrm{H}$ refleksi normal iken iğne EMG'de bilateral alt ekstremitelerde L3-S1 uyarımlı kaslarda istirahatte yoğun pozitif diken ve fibrilasyon potansiyelleri kaydedildi. İstemli kasıda normal ve seyrek yüksek amplitüdlü, polifazik, uzun süreli ve belirgin seyrelmiş MUP' ler mevcuttu.

Bulgular L3-S1 innerve kaslarda subakut dönem ön kök ön boynuz tutulumu ile uyumlu bulundu. Beyin omurilik sivisı (BOS) biyokimyası ve hücre sayımı normal olan hastaya $0.4 \mathrm{gr} / \mathrm{kg} / \mathrm{gün}$ dozunda 5 gün intravenöz immunglobulin (IVIG) tedavisi verildi ve fizik tedavi programına alındı.
Tedaviden ılımlı yanıt gören hastanın 1. ay kontrolünde kas güçlerinde tama yakın düzelme olduğu görüldü. Kontrol EMG'sinde denervasyon potansiyellerinin seyreldiği ve MUP’lerin normalleștiği görüldü.

\section{TARTIȘMA}

Morbid obezite prevalansının artışı ile birlikte bariatrik cerrahi prosedürlerinin sayısı her geçen gün artmakta ve nörolojik komplikasyonlarla daha fazla karşılaşılmaktadır. Obez bireylerin \%20\%30'unda operasyon öncesinde B1, B12, D vitaminleri, folat ve bakır eksiklikleri bulunmakta ve bu durum, operasyon sonrasi diyet değişimi, azalmış absorbsiyon, persistan kusma ve gastrik asit ve intrensek faktör kaybı nedeniyle nörolojik tablolara yol açabilmektedir ${ }^{3,8}$. Bizim hastamızda operasyon öncesi laboratuvar değerleri bilinmemekte idi ve operasyon sonrası erken dönemde B12 vitamini sınırda düşük bulunmuștu. Ancak literatürde nütrisyonel nörolojik komplikasyonların erken dönemde tiamin eksikliğine bağlı nöropati ve Wernicke ensefalopatisi şeklinde görülebileceği, B12 vitamini eksikliklerinde ise semptomların aylar veya yıllar sonra gelişmesinin beklendiği bildirilmiştir9.

Hepatik depolar hastayl birkaç ay ve muhtemelen yıllar boyunca korumak için yeterlidir ${ }^{10}$. Hastalar paresteziler, azalmış derin tendon refleksleri, güçsüzlük, pozisyon ve vibrasyon duyusu kaybı ile prezente olur 3,9 . Bizim hastamızda klinik bulgular uyumlu olmakla birlikte çok erken başlangıç ve vitamin takviyesi ile kliniğin düzelmemesi, aksine progrese olması bizi ileri incelemeye yöneltmişti.

GBS bariatrik cerrahinin çok nadir bir komplikasyonu olarak bildirilmiștir ve bildirilmiş vakalar çoğunlukla aksonal tiptedir ${ }^{2,11}$ Literatürde sadece bir poliradikülonöropati olgusu bildirilirken ${ }^{12}$ çalışmamıza benzer bir olgu Machado ve ark. 
tarafından bildirilmiş ve bu olguda alt ekstremitlerde aksonal bir polinöropati saptanırken proksimal güç kaybının hakim olduğu bir tablonun operasyondan 2 ay sonra geliştiği belirtilmiştir ${ }^{13}$. Olgumuzda şikayetlerin erken dönemindeki elektrofizyolojik incelemelerde alt ekstremitelerde simetrik duysal aksonal kayıp saptanmıştı. Ancak bu durum hastadaki obezite nedenli duysal potansiyellerin kaydedilememiş olabileceği şeklinde de yorumlanabilirdi. Takipte şikayetlerin 3. ayında kliniğimizde yapılan elektrofizyolojik incelemelerinde sinir iletim çalışmaları normal sınırlarda iken proksimal kas gruplarında çok yoğun denervasyon potansiyelleri kaydedilmişti. İstemli kasıda izlenen nörojenik MUP değişimleri ön kök ön boynuz tutulumunu göstermekte idi. Şikayetlerin hızlı gelişimi, laboratuvar değerlerinin normal olması bizi vitamin eksikliklerinde uzaklaștırdı. Öncesinde vitamin desteğine rağmen tablonun progrese olması ve süresinin tam olarak bilinmediği ancak 1 ay gibi olduğu anlaşılan progresyon süreci bizi enflamatuvar bir polinöropati tablosunu düşünmeye yöneltti. BOS bulgularının normal olması lomber ponksiyonun geç dönemde yapılmasına bağlandı.

Belirgin paraparezi nedenli verilen IVIG tedavisine de dramatik yanıt alındı. Literatürde bariatrik cerrahi sonrası gelişen nörolojik komplikasyonlar için 2 farklı mekanizma öne sürülmüştür. Bunların birincisi malabsorbsiyon sonrası gelișen vitamin ve mineral eksiklikleri iken ikinci hipotez ise enflamatuvar hasardır ${ }^{14}$. Bir çalışmada bariatrik cerrahi sonrası nöropati gelişen olgularda yapılan sural sinir biyopsilerinde aksonal hasara eşlik eden enflamatuvar değişimler izlenmiştir ${ }^{4}$. Bizim vakamı GBS' nin paraparezi varyant ${ }^{15}$ olabileceği gibi, ikinci hipotezi doğrular nitelikte nadir görülen bir poliradikülonöropati olgusu da olabileceği düșünülmüștür.

Sonuç olarak bariatrik cerrahi sonrası gelişen nörolojik komplikasyonlarda nutrisyonel eksikliklerin yanında enflamatuvar hasarın da göz önünde bulundurulması gerektiği ve bu vakaların kalıcı nörolojik hasarın önlenmesi açısından erken dönemde, multidisipliner bir şekilde takip ve tedavi edilmesi gerektiği görüşündeyiz.

Çıkar Çatışması Beyanı: Yazarlar çıkar çatışması olmadığını bildirmişlerdir.

Finansal Destek: Bu çalışma her hangi bir fon tarafından desteklenmemiştir.

Declaration of Conflicting Interests: The authors declare that they have no conflict of interest.

Financial Disclosure: No financial support was received.

\section{KAYNAKLAR}

1. Karmali S, Schauer P, Birch D, Sharma AM, Sherman V. Laparoscopic sleeve gastrectomy: An innovative new tool in the battle against the obesity epidemic in Canada. Can J Surg. 2010; 53: 126-32.

2. Chang CG, Helling TS, Black WE, Rymer MM. Weakness after gastric bypass. Obes Surg. 2002 Aug; 12: 592-7.

3. Landais A. Neurological complications of bariatric surgery. Obes Surg. 2014; 24: 1800-7.

4. Thaisetthawatkul P, Collazo-Clavell ML, Sarr MG, Norell JE, Dyck PJ. A controlled study of peripheral neuropathy after bariatric surgery. Neurology. 2004 Oct 26; 63: 1462-70.

5. Juhasz-Pocsine K, Rudnicki SA, Archer RL, Harik SI. Neurologic complications of gastric bypass surgery for morbid obesity. Neurology 2007; 68: 1843-50.

6. Yasawy ZM, Hassan A. Post bariatric Surgery Acute Axonal Polyneuropathy: Doing Your Best is Not Always Enough. Ann Indian Acad Neurol. 2017; 20: 309-12.

7. Şencan R, Utku U, Gök M. Bilateral Peroneal Neuropathy after Obesity. Surgery Turk J Neurol. 2015; 21: 110-11.

8. Gudzune KA, Huizinga MM, Chang HY, et all. Screening and diagnosis of micronutrient deficiencies before and after bariatric surgery. Obes Surg. 2013; 23: 1581-9.

9. Goodman JC. Neurological Complications of Bariatric Surgery. Curr Neurol Neurosci Rep. 2015 Dec; 15:7 9. 
10. Tack J, Deloose E. Complications of bariatric surgery: dumping syndrome, reflux and vitamin deficiencies. Best Pract Res Clin Gastroenterol. 2014; 28: 741-9.

11. Aluka KJ, Turner PL, Fullum TM. Guillain-Barré syndrome and postbariatric surgery polyneuropathies. JSLS. 2009; 13: 250-3.

12. Degterev DA, Suponeva NA, Bodunova NA, et all. A rare complication of bariatric surgery: Polyradiculoneuropathy as a type of Guillain-Barré syndrome. Ter Arkh. 2016; 88: 79-83.
13. Machado FC, Valério BC, Morgulis RN, Nunes KF, Mazzali-Verst S. Acute axonal polyneuropathy with predominant proximal involvement: an uncommon neurological complication of bariatric surgery. Arq Neuropsiquiatr. 2006 Sep; 64: 609-12.

14. Clark N. Neuropathy following bariatric surgery. Semin Neurol. 2010 Sep; 30: 433-5.

15. van den Berg B, Fokke C, Drenthen J, et all. Paraparetic Guillain-Barré syndrome. Neurology 2014; 82: 1984. 